STUDI

FRANCESI

\section{Studi Francesi}

Rivista quadrimestrale fondata da Franco Simone

160 (LIV | I) | 2010

II simbolismo. Nomi, aspetti, momenti. Studi in memoria di Ivos Margoni

\title{
Raymond Trousson, Voltaire 1778-1878
}

\section{Stefania Carli}

\section{OpenEdition}

Journals

\section{Edizione digitale}

URL: http://journals.openedition.org/studifrancesi/7242

DOI: $10.4000 /$ studifrancesi.7242

ISSN: 2421-5856

\section{Editore}

Rosenberg \& Sellier

\section{Edizione cartacea}

Data di pubblicazione: 1 avril 2010

Paginazione: 151

ISSN: 0039-2944

\section{Notizia bibliografica digitale}

Stefania Carli, «Raymond Trousson, Voltaire 1778-1878», Studi Francesi [Online], 160 (LIV | I) | 2010, online dal 30 novembre 2015, consultato il 11 janvier 2021. URL: http://journals.openedition.org/ studifrancesi/7242; DOI: https://doi.org/10.4000/studifrancesi.7242

Questo documento è stato generato automaticamente il 11 janvier 2021.

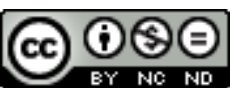

Studi Francesi è distribuita con Licenza Creative Commons Attribuzione - Non commerciale - Non opere derivate 4.0 Internazionale. 


\title{
Raymond Trousson, Voltaire 1778-1878
}

\author{
Stefania Carli
}

\section{NOTIZIA}

RAYMOND TROUSSON, Voltaire 1778-1878, Paris, Pups, 2008, pp. 673.

1 Raymond Trousson raccoglie in questo volume un centinaio di scritti di alcuni dei più illustri rappresentanti della letteratura francese del diciottesimo e del diciannovesimo secolo che hanno come tema portante l'analisi del personaggio Voltaire. Vi si trovano, solo per citarne alcuni, testi di Mercier, Chénier, La Harpe, Chateaubriand, Stendhal, Nodier, Musset, Balzac, Sand, Nerval, Michelet, Lamartine, Sainte-Beuve, Flaubert, Taine, Gautier, Brunetière et Hugo.

2 Nella sua ben documentata introduzione, Trousson si sofferma sullo studio della ricezione che le idee del grande rappresentante delle Lumières francesi hanno avuto nei primi cento anni successivi alla sua morte, avvenuta, come è noto, il 30 maggio 1778. Destinato a diventare presto una sorta di personaggio teatrale o di eroe da romanzo, tra il 1778 e il 1878 Voltaire viene spesso strumentalizzato, come accade per esempio negli anni della Rivoluzione francese, osannato, ma anche condannato. Inevitabilmente collegato a qualsiasi disputa politica e religiosa, egli è attaccato con particolare veemenza negli anni della Restaurazione. I romantici non apprezzano del tutto la sua genialità e, soprattutto dal punto di vista dell'estetica che soggiace alla sua produzione letteraria, lo considerano un autore troppo classico.

3 Additato come un distruttore dei valori e della morale, Voltaire rimane però sempre attuale, sino ad essere esaltato nel 1848 in special modo da Lamartine. Pur restando spesso in bilico tra l'elogio e la condanna, durante il regno di Napoleone III, Voltaire diventa quasi un simbolo, sebbene criticato e disprezzato da autori quali Baudelaire, Barbey d'Aurevilly e i fratelli Goncourt. Persino la celebrazione del centenario della sua morte scatena polemiche e dispute alle quali Victor Hugo, che negli anni della sua 
vecchiaia spicca tra i maggiori sostenitori di Voltaire, tenta di tenere testa con un discorso che ne esalta l'immortalità.

4 Eppure, come dimostra bene Raymond Trousson nella sua introduzione, nonostante le diatribe, l'autore di Candide continuerà negli anni ad insediarsi nella memoria dei Francesi, diventando l'indiscusso nemico dell'ingiustizia e dell'intolleranza. 